\title{
PESTICIDAL REPERCUSSIONS OF DIFFERENT PLANTS OIL ON LARVAE AND ADULT of Tribolium confusum JAQUELIN DU VAL
}

\author{
Nora A. Al-Qarni ${ }^{1}$, Abdulrahman A FarajAllah ${ }^{2}$, Mona Mahmoud ${ }^{3}$, Khalid M Alghamdi ${ }^{3}$, \\ Habeeb M Al-Solami ${ }^{3}$, Yasir Anwar ${ }^{3 *}$
}

${ }^{1}$ Department of Biology, College of Adhma, University of Umm AlQura, Makkah Al-Mukkaramah.

${ }^{2}$ Department of Biology, Batterjee Medical College for Science and Technology, Jeddah

${ }^{3}$ Department of Biological Sciences, Faculty of Science, King Abdul-Aziz University, Jeddah

Received - June 04, 2018; Revision - July 18, 2018; Accepted - August 09, 2018

Available Online - August 10, 2018

DOI: http://dx.doi.org/10.18006/2018.6(4).661.668

\section{KEYWORDS}

Stored grain pests

Oils

Fumigation

Confused flour beetle

\begin{abstract}
Continues use of synthetic insecticides has resulted in resistance towards insecticides. Therefore, present study was conducted to evaluate the biocontrol potential of three essential oil fumigation viz., Zea mays, Zingiber officinale, and Allium sativum against flour beetle Tribolium confusum. For this purpose, fourth larval instars and adults were treated with a different concentration of selected essential oils. Results of present study revealed that after 24 and 48 hours, fourth larval instars were more susceptible to the used plants oil fumigation as compared to the adults. Among the tested oils, fumigation by ginger oil showed highest mortality rate on the fourth larval instars and adults after 24 and 48 hours and it was followed by the fumigation by garlic essential oil. Therefore, from these results, it can be conclude that essential oils fumigation could be use for the biocontrol of flour beetle Tribolium confusum.
\end{abstract}

* Corresponding author

E-mail: yanwarulhaq@kau.edu.sa; yasirpcsir2006@gmail.com (Yasir Anwar)

Peer review under responsibility of Journal of Experimental Biology and Agricultural Sciences.

Production and Hosting by Horizon Publisher India [HPI] (http://www.horizonpublisherindia.in/).

All rights reserved.
All the article published by Journal of Experimental Biology and Agricultural Sciences is licensed under a Creative Commons Attribution-NonCommercial 4.0 International License Based on a work at www.jebas.org.

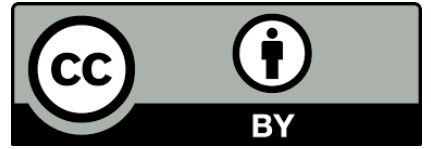




\section{Introduction}

Mycoplasmosis are the infectious diseases caused by smallest wall less prokaryotes known as mycoplasma (Nicholet, 1996; Kumar et al., 2011a). It is now an emerging threat and transboundary epidemiological disease posing a worldwide regulation on small ruminant productions and hence huge economic constraints for farmers and small ruminant rearing countries (Thiaucourt \& Bolske, 1996; Ruffin, 2001; Kumar et al., 2011a; Chakraborty et al., 2014; Prats-van der Ham et al., 2015). The pathogens of these diseases Stored grain pests are the major problem for stored grain and their commercial products throughout the world because they reduce the quantity and quality of grains. Storage of grains is an integral part of the post-harvest system since the food material passes on its way from field to the consumers. About 5-15\% of the total weight of all cereals, oilseeds and pulses is lost after the harvest (Anonymous, 1989). The estimated annual losses by insects and rodents in transit or during storage are about $10 \%$ in North America and 30\% in Africa and Asia. In India, the annual loss due to insect pests is about 26\% (Anonymous, 2015). However, the food grains account for 20-25\% damage by storage insect pests (Rajashekar et al., 2010).

Mostly post harvest losses are because of unsuitable traditional or modern storage facilities. These losses constitute a major problem that is due to infestation by a great horde of insect pests of stored products. The cryptic, hideous creatures caused quantitative and qualitative losses (Upadhyay \& Ahmed, 2011). Most probably, it occurred due to unavailability of proper storage facilities especially in the rural regions. This unavoidable damage of grains is due to stored grain insect's pests, which contaminate during storage, shipping and transportation. These insect pests considered a serious constraint in all parts of the globe especially in the $3^{\text {rd }}$ world and developing countries (Talukder et al., 2004; Duby et al., 2008). The infestation by these stored grain pests always leads to depreciation in weight and quality of the stored products (Rayhan et al., 2014). In addition, heavy infestation might induce a great change of fungal and other dangerous microflora infestation (Koul et al., 2008; Rajashekar et al., 2012).

Confusion beetles (Tribolium confusum) are the members of the darkling beetle's order Coleoptera, family Tenebrionidae. Its name is due to its confusion with the rusty red flour beetle $T$. castaneum Herbst, T. destructor and T. ferrugineum Fab. Currently it is a worldwide insect pest of great economic significance in stored product. It is the most common pest of flourmills, cereal products, groundnuts, cacao, spices, dried figs and dates, copra, dried yam, palm kernels, various nuts, oilseeds and cottonseed. Its rapid development and readiness to breed in the laboratory have made it a popular tool in physiological and genetic studies (Nenaah, 2014).
The documented and authenticated facts about the scare of pesticide residues in storage commodities and the awareness of the public demand has made it urgent for the FDA to embrace and advocate more emphasis for the public health. Therefore, many researchers have been attracted towards the novel, promising potentials of the green pesticides that contribute in reducing insect pest populations (Imran et al., 2015; Lal et al., 2017). Recently various researches have been conducted on the use of plant extracts and their byproducts against harmful storage insect pests and result of these studies proved that these extract might have many active components that works as a biopesticides many. These researches proved that plant based pesticides might be suitable alternatives for the biocontrol of many insect pests (Nawrot \& Harmatha, 1994; Adam et al., 1998; Kabera, 2004). These plants extract are rich in enormous compounds and active ingredients that show anti-feedant, hideous, sterilization and lethal deleterious or malformation effects on a multitude of insect pests (Isman, 2006).

The desired lethal toxicity of insecticides on stored grain pests may be manifested as contact or through fumigation action; albeit the effective toxicity of most essential oils has been sharpened lately and gained encouraging appraisals for the applied usage of plant products as potential pesticides on a variety of stored grain pests (Golob et al., 1999; Weaver \& Subramanyam, 2000). Many essential oils including ginger oil (Zingiber officinale); garlic oil (Allium sativum); corn oil (Zea maize); soybean oil (Glycine max); castor oil (Ricinus communis); sunflower oil (Helianthus annuus); cardamom oil (cardamomum) have been successfully used as control agents against variety of stored grains pests. These essential oils were used to evaluate their residual, repellent and fumigation efficacy on immature and adults of different grain pests. Many encouraging results were reported hailing the pivotal role of plant extracts and byproducts as urgent factors in the arena of combating the stored grain pests (Prakash \& Rao, 1997). Information regarding the use of essential oil fumigation against the confused flour beetles is in scarcity. Therefore, the present study has been undertaken to investigate the efficacy of selected plant oils viz., corn, ginger and garlic at different concentrations against the fourth instar larvae and adults of the confused flour beetles.

\section{Materials and Methods}

\subsection{Extraction of oil}

The corn, ginger, and garlic essential oils were extracted by following below given method. 


\subsubsection{Corn oil using Soxhlet apparatus}

Corn oil was extracted from ground corn seed using ethanol as the solvent. Optimal conditions were a solvent-to-solids ratio of 4 $\mathrm{mL} / \mathrm{g}$ corn, an ethanol concentration of $100 \%, 30 \mathrm{~min}$ of extraction time, and a temperature of $50^{\circ} \mathrm{C}$. A three-stage extraction was carried out, where the same corn was exposed to fresh ethanol. Moisture was absorbed linearly by ethanol from the corn in successive stages, which, in turn, decreased oil yield and increased nonoil components in the extract.

\subsubsection{Ginger oil}

Ginger oil was extracted by Soxhlet extraction, with the optimized operational condition. The operational conditions include an optimized sample (Ginger corm), temperature $\left(70^{\circ} \mathrm{C}\right.$ to $80^{\circ} \mathrm{C}$ ), extraction time (1 to $1.30 \mathrm{hr}$ ), and ratio of ginger to solvent (50 gm ginger : $200 \mathrm{ml}$ Ethanol).

\subsubsection{Garlic oil}

The extraction of garlic oil was carried out with a Soxhlet extractor using n-hexane (boiling point of $40^{\circ} \mathrm{C}-60^{\circ} \mathrm{C}$ ) for six hours. The oils were obtained after the solvent was removed under reduced temperature and pressure and refluxing at $70 \mathrm{C}$, to remove any excess solvent used for the oil extracted. The extracted garlic oil was stored in refrigerator freezer at $2{ }^{\circ} \mathrm{C}$ for subsequent physicochemical analyses (Warra et al., 2011).

\subsection{Sample collection}

Larvae and adults were carefully reared under laboratory conditions at the department of biological Sciences, insects have been maintained for many generations in incubators under darkness conditions at $27 \pm 3^{\circ} \mathrm{C}$ and $65 \pm 5 \%$ R.H. Experimental animals were fed with a mixture of whole-wheat flour and brewer's yeast 4:1. Fourth instars and ten-days post-emerging adults were used for all experiments.

\subsection{Fumigant toxicity test}

To determine the fumigant toxicity of the selected three plant oils on the fourth larval stage and adults of $T$. confusum, the Whatman filter papers No. 1 cut into circles with $2-\mathrm{cm}$ diameter pieces then impregnated with oil at 25, 50, 100, 200, and $400 \mu \mathrm{L} / \mathrm{L}$ concentrations. The impregnated filter papers were attached to the undersurface of the screw cap of a glass vial (1L). The caps screwed tightly onto a vial containing 10 insects. Each concentration were replicated four times and kept in darkness in the incubators at $27 \pm 3^{\circ} \mathrm{C}$ and $65 \pm 5 \%$ R.H. The percentage mortality was determined after 24 and $48 \mathrm{hrs}$ post-treatment by counting the number of completely dead insects.

\section{Results}

The data obtained from both fourth instar larvae and adults were statistically analyzed to reveal the efficacy of the three plant oils on the confused flour beetle (CFB).

\subsection{Effect of Essential oils on $4^{\text {th }}$ Larval Instars of $T$. confusum}

\subsubsection{The effect of corn oil fumigation on $4^{\text {th }}$ Larval Instars of the $T$. confusum}

The treatment of $4^{\text {th }}$ larval instars of $T$. confusum with corn oil at different concentration and the corresponding recorded percentage mortality is shown in Table 1 . The results of study revealed that the percentage mortality increased with increasing the

Table 1 Effect of various essential oils fumigation on mortality percentage of $4^{\text {th }}$ larval instars of CFB

\begin{tabular}{|c|c|c|c|c|c|c|}
\hline \multirow{3}{*}{ Dose $(\mu \mathrm{L} / \mathrm{L})$} & \multicolumn{6}{|c|}{ Mortality Percentage } \\
\hline & \multicolumn{2}{|c|}{ Corn Oil } & \multicolumn{2}{|c|}{ Ginger Oil } & \multicolumn{2}{|c|}{ Garlic Oil } \\
\hline & $24 \mathrm{hrs}$ & $48 \mathrm{hrs}$ & $24 \mathrm{hrs}$ & $48 \mathrm{hrs}$ & $24 \mathrm{hrs}$ & $48 \mathrm{hrs}$ \\
\hline 25 & 30 & 30 & 32 & 45 & 32 & 55 \\
\hline 50 & 32 & 32 & 35 & 52 & 37 & 62 \\
\hline 100 & 37 & 45 & 37 & 54 & 40 & 67 \\
\hline 200 & 47 & 47 & 42 & 55 & 47 & 69 \\
\hline 400 & 52 & 57 & 52 & 62 & 50 & 85 \\
\hline${ }^{\mathrm{a}}$ Control & 10 & 10 & 10 & 10 & 10 & 10 \\
\hline slope & 0.49 & 0.65 & 0.43 & 0.71 & 0.54 & 1.09 \\
\hline$(\mathrm{Chi})^{2}$ & 0.03 & 0.27 & 0.004 & 0.33 & 1.93 & 1.96 \\
\hline $\mathrm{LC}_{50}$ & 301 & 147.9 & 391.9 & 16.47 & 288.9 & 28.96 \\
\hline
\end{tabular}

$\left({ }^{a}\right)$ Corrected with Abbot's formula, (1925)

Journal of Experimental Biology and Agricultural Sciences http://www.jebas.org 
concentrations ( $\mu \mathrm{L} / \mathrm{L}$ air) of oil and duration from $24 \mathrm{hrs}$ to $48 \mathrm{hrs}$ as indicated in Probit analysis (Figure 1A). The calculated slope value of the Probit analysis curve was 0.49 and 0.65 after 24 and $48 \mathrm{hr}$ respectively. Result presented in figure $(1 \mathrm{~A})$ indicated that as time increased from 24 to $48 \mathrm{hrs}$ the corn oil is more sensitive in controlling the $4^{\text {th }}$ instars larvae. Non-significant differences were reported between the various doses of oil and mortality percentages $(\mathrm{P}<0.05)$ as shown by Chi 2 ( $0.03 \& 0.27)$. The lethal concentration at which $50 \%$ of the population responded (LC50) was recorded 301ppm for $24 \mathrm{hrs}$ and $147.9 \mathrm{ppm}$ for $48 \mathrm{hrs}$. This indicated that corn oil was not much effective in controlling the $4^{\text {th }}$ instars larvae of the $(\mathrm{CFB})$ as time increased from 24 to $48 \mathrm{hrs}$.

\subsection{Effect of Ginger oil fumigation on $4^{\text {th }}$ Larval Instars of the $T$. confusum}

Effect of different concentrations of ginger oil on percentage mortality of $4^{\text {th }}$ larval instars of $T$. confusum has been represented in Table 1. Like maize, percentage mortality increased with the increasing ginger oil concentration (ppm) and exposure time from $24 \mathrm{hrs}$ to 48 hrs. The calculated slope value from the curve of Probit analysis was 0.43 and 0.71 after 24 and $48 \mathrm{hrs}$ (Figure 1B). Further, result of present study suggested that the ginger oil was more effective in controlling the $4^{\text {th }}$ instar larvae of the (CFB) and this effectiveness increased with increasing time from 24 to $48 \mathrm{hrs}$. The differences between various doses of essential oil and mortality percentages were not significant $(\mathrm{P}<0.05)$ as shown by $\mathrm{Chi} 2$ and it was reported $0.004 \& 0.33$ after 24 and 48 hrs respectively, as compared to control. The concentration at which $50 \%$ population responded (LC50) was $391.9 \mathrm{ppm}$ for $24 \mathrm{hrs}$ and $16.47 \mathrm{ppm}$ for 48 hrs. This indicated that ginger oil was highly effective in controlling the $4^{\text {th }}$ instars larvae of the (CFB) flour beetle as time increased from 24 to $48 \mathrm{hrs}$.

\subsubsection{Effect of Garlic oil fumigation on $4^{\text {th }}$ Larval Instars of the $T$. confusum}

The treatment of the $4^{\text {th }}$ larval instars of $T$. confusum with garlic oil at different concentration and the corresponding recorded percentage mortality is shown in Table 1. The results showed that the percentage mortality has been increased with the increasing essential oil concentration (ppm) and exposure time from 24 and 48hrs post-treatment as indicated by Probit analysis (Figure 1C). The calculated slope value from the curve of Probit analysis was 0.54 and 1.09 after 24

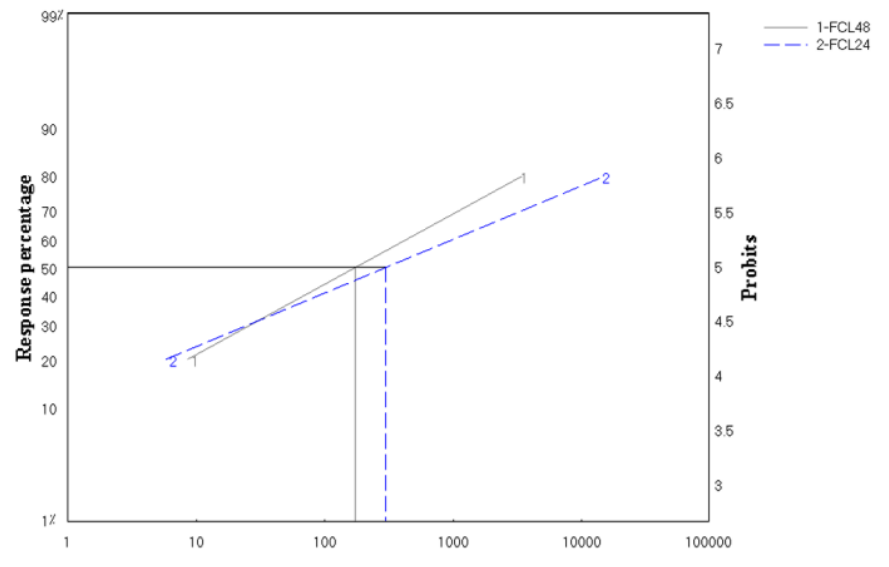

1A. Corn Oil
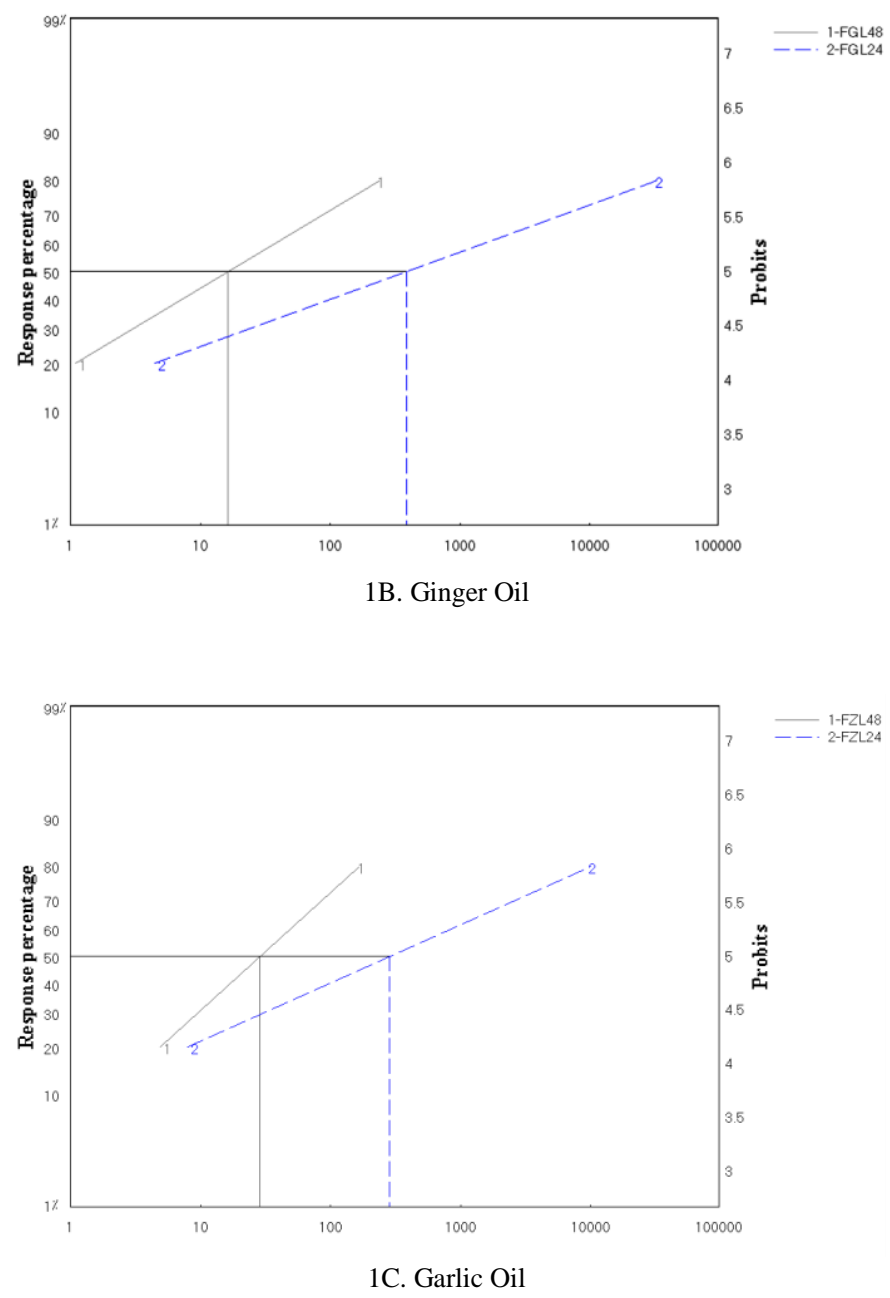

Figure 1 Probit analysis showing the relationship between the fumigation mortality percentage and the doses of select oil on $4^{\text {th }}$ larval instar of the (CFB); FCL (Fumigant effect of corn oil on the $4^{\text {th }}$ instars Larvae) 
Table 2 Effect of various essential oils fumigation on mortality percentage of CFB adults

\begin{tabular}{|c|c|c|c|c|c|c|}
\hline \multirow{3}{*}{ Dose $(\mu \mathrm{L} / \mathrm{L})$} & \multicolumn{6}{|c|}{ Mortality Percentage } \\
\hline & \multicolumn{2}{|c|}{ Corn Oil } & \multicolumn{2}{|c|}{ Ginger Oil } & \multicolumn{2}{|c|}{ Garlic Oil } \\
\hline & $24 \mathrm{hrs}$ & $48 \mathrm{hrs}$ & $24 \mathrm{hrs}$ & $48 \mathrm{hrs}$ & $24 \mathrm{hrs}$ & $48 \mathrm{hrs}$ \\
\hline 25 & 30 & 32 & 31 & 32 & 30 & 34 \\
\hline 50 & 31 & 34 & 33 & 34 & 31 & 38 \\
\hline 100 & 33 & 36 & 35 & 41 & 32 & 40 \\
\hline 200 & 34 & 37 & 50 & 52 & 42 & 57 \\
\hline 400 & 38 & 40 & 90 & 98 & 80 & 90 \\
\hline${ }^{\mathrm{a}}$ Control & 10 & 10 & 10 & 10 & 10 & 10 \\
\hline slope & 0.9 & 0.53 & 0.98 & 1.56 & 1.13 & 1.38 \\
\hline$(\mathrm{Chi})^{2}$ & 0.13 & 0.79 & 11.35 & 16.4 & 2.71 & 0.32 \\
\hline $\mathrm{LC}_{50}$ & 185 & 77.8 & 118.45 & 64.4 & 89.8 & 50.1 \\
\hline
\end{tabular}

$\left({ }^{a}\right)$ Corrected with Abbot's formula, (1925)

and $48 \mathrm{hr}$ respectively. The differences between doses of oil and the mortality percentages were significant at $\mathrm{P}<0.05$ level of probability as shown by Chi2 and it was reported 1.93 after $24 \mathrm{hrs}$ and 1.96 after $48 \mathrm{hrs}$ in comparison to the control. The concentration at which $50 \%$ of the population responded (LC50) was recorded $288.9 \mathrm{ppm}$ for $24 \mathrm{hrs}$ and $28.96 \mathrm{ppm}$ for $48 \mathrm{hrs}$. This indicated that garlic oil have significant effect on the $4^{\text {th }}$ instars larval mortality.

\subsection{Effect of various essential oil on Adult's stage}

\subsubsection{Effect of Corn oil fumigation on Adult stage}

Mortality percentages in treatment containing adults of $T$. confusum along with different concentrations of corn essential oil are presented in Table 2. Like other treatments, here also percentage mortality increased with the increasing the doses (ppm) of corn oil and time duration from 24 hrs to $48 \mathrm{hrs}$ posttreatment as indicated by probit analysis (Figure 2A). The calculated slope value from the curve of probit analysis was 0.49 and 0.53 after 24 and 48 hrs respectively. Further, it was reported that corn oil was not that much effective in controlling the CFB adults. The differences between doses of oil and the mortality percentages were not significant as shown by Chi2. The concentration at which $50 \%$ of the population responded (LC50) was recorded $185 \mathrm{ppm}$ for $24 \mathrm{hrs}$ and $77.8 \mathrm{ppm}$ for $48 \mathrm{hrs}$.

\subsubsection{Effect of Ginger oil fumigation on Adult stage:}

Effect of ginger essential oil on the adult mortality of $T$. confusum has been represented in Table 2 . Result of study revealed that percentage of mortality increased with increasing the concentration of essential oil (ppm) and time duration (Figure 2B). The calculated slope value from the curve of probit analysis was 0.98 and 1.56 after 24 and $48 \mathrm{hrs}$ respectively. This indicated that the ginger oil was quite effective in controlling the CFB Adult. The differences between doses of oil and the mortality percentages were not significant at $\mathrm{P}<0.05$ level of probability as shown by Chi2 and this value was reported 11.35 \&16.4 after 24 and $48 \mathrm{hrs}$ respectively in comparison to the control. The concentration at which $50 \%$ population responded (LC50) was recorded $118.45 \mathrm{ppm}$ for $24 \mathrm{hrs}$ and $64.4 \mathrm{ppm}$ for 48 hrs exposure. These results suggested that ginger oil have significant effect on CFB adults mortality and among the tested essential oil, this is highly effective one.

\subsubsection{Effect of Garlic oil fumigation on Adult stage:}

Results presented in table 2 revealed a significant effect of garlic essential oil on $T$. confusum adult mortality. Further, mortality percentage increased with increasing essential oil concentrations (ppm) and exposure time from $24 \mathrm{hrs}$ to $48 \mathrm{hrs}$. The calculated slope value from the curve of probit analysis was 1.13 and 1.38 after 24 and $48 \mathrm{hr}$ respectively (Figure 2C). This indicated that the garlic oil was highly effective in controlling CFB adults and this effectiveness increased from 24 to $48 \mathrm{hr}$. The differences between doses of oil and the mortality percentages were significant at $(\mathrm{P}<0.05)$ level of probability as shown by $\mathrm{Chi} 2$ and it was reported 2.71 after $24 \mathrm{hrs}$ of exposure and 0.32 for $48 \mathrm{hrs}$ of exposure, in comparison with the control. The concentration at which $50 \%$ of the population responded (LC50) was recorded $89.8 \mathrm{ppm}$ after $24 \mathrm{hrs}$ and $50.1 \mathrm{ppm}$ after $48 \mathrm{hr}$. This indicated that 

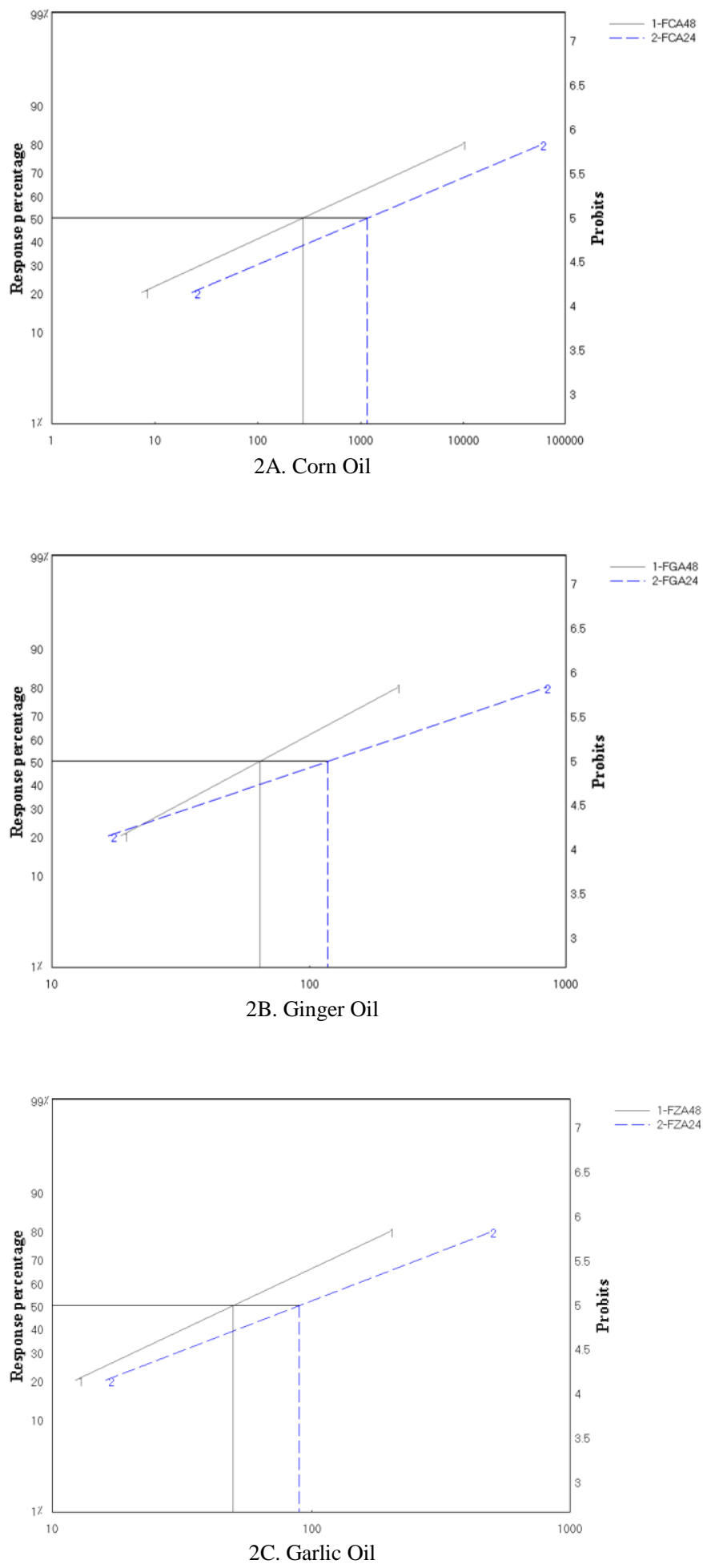

Figure 2 Probit analysis showing the relationship between the fumigation mortality percentage and doses of selected oil on adults of CFB; FCA (Fumigant effect of Corn oil on the adults) garlic oil was quite effective in controlling the flour beetle and this effectiveness increased with the increasing exposure time increased from 24 to $48 \mathrm{hrs}$.

\section{Discussion}

Results of study revealed significant effect of used essential oil fumigation on $4^{\text {th }}$ Larval Instars and adult of T.confusum. Further, among these three essential oils, ginger and garlic essential have great CFB management potential and it reported highest on the highest concentration (400ppm) of both essential oils. The lethal effect of garlic acid on $4^{\text {th }}$ instar larvae was $52 \%$ after 24 hrs exposure at $400 \mathrm{ppm}$ concentration and this increased when the exposure time was increased to $48 \mathrm{hrs}$. While in case of adults, ginger oil gave $90 \%$ mortality after $24 \mathrm{hrs}$ and it increased to $98 \%$ after $48 \mathrm{hrs}$ of exposure. Results of present study are in agreement with the findings of Mikhaiel (2011), those who have reported significant inhibitory effect of ginger oil against T. castaneum larvae. Similarly, Talukder \& Khanam (2011) also reported that ginger extracts were most effective as a fumigant agent against S. oryzae. Lethal effect of ginger essential oil was followed by the essential oil of garlic and corn essential oils. Corn oil was found least effective with 52\% and 57\% $4^{\text {th }}$ instar larval mortality while it was reported only $38 \%$ and $40 \%$ for adults after 24 and 48 hrs respectively. These results are in agreement with the findings of Kim et al. (2012) and Wang et al. (2014) who found that the fumigant activities of Cinnamom umcassia and Allium sativum seemed to be stronger on 6th instars larvae than on adults of the darkling beetle, Alphitobius diaperinus.

From the result of study, it can be conclude that plant-based biopesticide can be used as an alternate of commercial chemical insecticides. These biopesticides are not only ecofriendly but also have significant biocontrol potential. Further studies are required for mass scale application of these plant-based biopesticide.

\section{Acknowledgements:}

The authors would like to extend their gratitude to the Deanship of Scientific Research at King Abdul-Aziz University for their financial support. In addition, our deep thanks goes to the Department of Biological Sciences (Girl's Section) College of Science at King Abdul-Aziz University.

\section{Conflict of Interest}

The authors declare that there is no conflict of interest regarding the publication of this review paper. 


\section{References}

Abbott WS (1925) A method for computing effectiveness of insecticides. Journal of Economic Entomology 18: 265-269.

Adam K, Sivropoulou A, Kokkini S, Lanaras T, Arsenakis M (1998) Antifungal activities of Origanum vulgare subsp. hirtum, Mentha spicata, Lavandula angustifolia and Salvia Jruiticosa essential oils against human pathogenic fungi. Journal of Agricultural and Food Chemistry 46: 1739-1745.

Anonymous (1989) Proceedings of the 18th International Course on Plant Protection. International Agricultural Centre, Wageningen, The Netherlands.

Anonymous (2015) Vision 2050. Directorate of Weed Research (ICAR), Jabalpur (MP), 32p.

Dubey NK, Srivastava B, Kumar A (2008) Current status of plant products as botanical pesticides in storage pest management. Journal of Biopesticide 1: 182-186.

Golob P, Moss C, Dales M, Fidgen M, Evans J, Gudrups (1999) The use of spices and medicinals as bioactive protectants for grains. Food and Agricultural Organization of the United Nations, Rome, 95 :531- 536.

Imran F, Mansoor-ul-Hasan, Muhammads S, Shahzad S (2015) Evaluating the potential of some plant extracts along with new chemistry insecticides thiamethoxam and emamectin benzoate against Cryptolestes ferrugineus. International Journal of Scientific and Research Publications 5:1-4.

Isman MB (2006) Botanical insecticides, deterrents and repellents in modern agriculture and an increasingly regulated world. Annual Review of Entomology 51: 45-66.

Kabera NJ (2004) Contribution to the chemical and essential oils of Lippia multiflora and Cymbopogon giganteus of Togo. University of Lomé, Pp.8-20.

Kim JR, Haribalan P, Son BK, Ahn YJ (2012) Fumigant Toxicity of Plant Essential Oils against Camptomyia corticalis (Diptera: Cecidomyiidae). Entomological Society of America 105:1329-1334.

Koul O, Walia S, Dhaliwal GS (2008) Essential oils as green pesticides: potential and constraints. Biopesticide International 4: $63-84$

Lal M, Ram B, Tiwari P (2017) Botanicals to Cope Stored Grain Insect Pests: A Review. International Journal of Current Microbiology and Applied Sciences 6: 1583-1594

Mikhaiel AA (2011) Potential of some volatile oils in protecting packages of irradiated wheat flour against Ephestia kuehniella and Tribolium castaneum. Journal of Stored Products Research 47: 357-364.

Nawrot J, Harmatha J (1994) Natural products as antifeedants against stored product insects. Post Harvey News Information, 5: $17-21$

Nenaah GE (2014) Chemical composition, toxicity and growth inhibitory activities of essential oils of three Achillea species and their nano-emulsions against Tribolium castaneum (Herbst). Industrial Crops and Products 53 : 252-260

Prakash A, Rao J (1997) Botanical pesticides in agriculture. CRC Lewis Publishers Boca Raton, pp. 24-26.

Rajashekar Y, Bakthavatsalam N, Shivanandappa T (2012) Botanicals as grain protectants. Psyche: A Journal of Entomology Article ID 646740, 13 pages. DOI: http://dx.doi.org/10.1155/2012/646740.

Rajashekar Y, Gunasekaran N, Shivanandappa T (2010) Insecticidal activity of the root extract of Decalepis hamiltonii against stored product insect pests and its application in grain protection. Journal of Food Science and Technology 47: 310-314.

Rayhan MZ, Das S, Sarka RR, Adhikary SK, Tania SN, Islam MM, Rabbani MG (2014) Bioefficacy of neem, mahogoni and their mixture to protect seed damage and seed weight loss by rice weevil in storage. Journal of Biodiversity and Environmental Sciences 5: 582-589.

Talukder D, Khanam LAM (2011)The Fumigant Toxicity Of Four Plant Based Products Against Three Stored Product Pests. International Journal of Sustainable Crop Production 6 :6-9.

Talukder FA, Islam MS, Hossain MS, Rahman MA, Alam MN (2004) Toxicity effects of botanicals and synthetic insecticides on Tribolium castaneum (Herbst) and Rhyzopertha dominica (F.). Bangladesh Journal of Environmental Sciences 10 : 365-37.

Upadhyay RK, Ahmad S (2011) Management strategies for

Journal of Experimental Biology and Agricultural Sciences http://www.jebas.org 
control of stored grain insect pests in farmer stores and public warehouses. World Journal of Agriculture Sciences 7 : 527-549.

Wang X, Li Q, Shon L, Yang J, Cheng H, Jiang S, Jiang C, Wang H (2014) Fumigant, contact, and repellent activities of essential oils against the darkling beetle, Alphitobius diaperinus. Journal of Insect Science 14:1-11.
Warra AA,Wawata IG, Hassan LG, Gunu SY, Aujara KM (2011) Extraction and physicochemical analysis of some selected Northern Nigerian industrial oils. Archives of applied science research 3: 536-541.

Weaver D, Subramanyam BH (2000) Botanicals. In: Alternatives to pesticides in stored-product IPM, Kluwer Academic Publishers, Dordrecht. pp. 303-320. 